\title{
Energy Resources of the Caspian Region and the Significance of Turkey for Europe's Energy Security
}

\section{Gourban Alekperov *}

Turkey's strategic position as a country located between Orient and Occident, situated on the emerging route between East and West, has been among the most significant factors highlighted by the extensive research literature focusing on the country's intention to join the European Union. In this context, of course, Turkey's strategic importance for the West is also pointed out - the country's status as the "Western fortress" in the Middle East, a region shaken by constant disturbances. The term "security" not only includes military and economic components, but, increasingly, also a secure supply of essential resources of energy. This essay will focus on this final aspect.

\section{Energy Resources in the Caspian Region and their Significance for Europe}

With the collapse of the Soviet Union, nine former USSR republics in the Caspian region-Russia, Armenia, Azerbaijan, Georgia, Turkmenistan, Kazakhstan, Kyrgyzstan, Uzbekistan, and Tajikistan - gained their independence and were individually given the rights and duties of sovereign states. Most of the countries of this region, including Iran, which is also among the states abutting the Caspian Sea, have rich oil and gas resources at their disposal. Since in recent years the quantities of these resources have become the subject of political polemic and of so-called "oil diplomacy" in these respective countries, one can only speak of relative numbers at best. According to various estimations, the proven oil reserves in the region are somewhere between two and seven billion tons. These estimations also conclude that the Caspian region contains about five to ten percent of all the oil reserves in world. For the purpose of comparison, it must be mentioned that Saudi Arabia alone has more than twenty-five percent of all proven oil reserves on the planet at its disposal. In the area of gas reserves, the Caspian region accounts for only three to five percent of global reserves. In sum, in the case of the Caspian region, one cannot speak of a new or another Persian Gulf, even if some authors would love to see their respective home countries arise as a new Kuwait or Oman.

According to these estimations, one can see that the energy resources of the Caspian region are on the same level as those of the North Sea. Maybe there is one little difference: the actual development of the energy resources of the North Sea, which form the primary reserves of the European Union, is much more advanced. In the case of the Caspian region, there possibly exist up to 28 billion tons of oil reserves as well

Gourban Alekperov, a citizen of Azerbaijan, is completing his Ph.D. at the University of Bochum in Germany. He is a recent graduate of the Leaders' Course at the George C. Marshall European Center for Security Studies. 
as enormous natural gas reserves (in addition to the already proven reserves) waiting for development and exploitation.

The comparison to the North Sea does not come out of the blue. Due to these resources, the European market's dependence on supplies from the Gulf region and from Russia was significantly reduced during the 1980s and until the end of the 1990s. However, the fact that there is an asymmetry between the available resources and the high volume of production is a problem for Europe for which a solution has to be found within the next decade. This is necessary in order to avoid the development of dependency on a single supplier. Furthermore, calculations in terms of energy policy also have to take into account the increasing demands of Southeast Asia. This region, with its dynamic economic development, will probably become the major importer of energy sources from the Persian Gulf region.

In such a case, the significance of the Caspian region for Europe will increase. Even if the European Union, with its fifteen member states, can live today - at least in the short or medium term-without exploiting the energy sources of the Caspian region, the situation will change dramatically after the accession of thirteen new member states. The majority of the new EU member states can be characterized by a high degree of unilateral dependency on energy supplies from Russia. This fact-as well as various other factors, such as the possibility of political instabilities in the Caspian region - was already noticed by the EU commission in the mid-1990s. The EU commission, demanding a more active EU engagement policy in the Caspian region, summarized its approach to the region in the following way:

- Support for independence and territorial integrity of the newly established states in the region;

- Consolidation of democratic institutions and human rights as a basis for security and peace;

- Decreasing the number of conflicts by means of political and economic reforms, which highlights the importance of the European Union as an impartial donor and partner for investment and commerce;

- Support for economic transformation in accordance with the principles of sustainability and environmental responsibility;

- Active participation of one's own economy in the decision-making processes with respect to investment, energy, and mining as well as with regard to future pipeline routes;

- Development of a stronger profile of the European Union in the entire region through a more intensified political dialogue.

Table 1 clearly shows the dependency of the new candidates for EU membership on imported energy: 
Table 1: Percentage of energy imports from Russia among the candidates for EU membership (1998, in percentage)

\begin{tabular}{lcr}
\hline Country & Oil (\%) & Gas (\%) \\
\hline Bulgaria & 98.5 & 99.7 \\
Estonia & 85.4 & 100 \\
Latvia & 105.4 & 106.4 \\
Lithuania & 87.8 & 100.0 \\
Malta & 99.9 & 0.0 \\
Poland & 96.6 & 66.8 \\
Rumania & 43.9 & 25.3 \\
Slovakia & 99.8 & 99.1 \\
Slovenia & 108.6 & 99.2 \\
Czech Republic & 99.8 & 99.1 \\
Turkey & 90.1 & 94.6 \\
Hungary & 80.9 & 72.4 \\
Cyprus & 98.8 & 0.0 \\
\hline
\end{tabular}

In 1998, the European Council agreed upon a common declaration on the European Union's engagement in the Caspian region. In this document, aside from the main focus (which was on the energy sector), the paragraph on the routes of the pipelines is particularly remarkable, because here the EU distances itself from the geopolitical and geo-strategic way of thinking and leaves the strategic decisions on the pipelines largely up to commercial calculations made by the affected corporate groups.

The European Energy Charter is one of the most important instruments of EU policy toward the Caspian region. It was signed by the EU and fifty-one countries in December 1991. The basic idea of the Charter was to create favorable conditions for incipient economic development in Eastern Europe and the former Soviet Union. The final plenary meeting of the European Energy Charter Conference, which was held in Lisbon on 16-17 December 1994, passed the European Energy Charter Contract. The signatories of this contract included, beside the EU member states, all Eastern European countries, the members of the Commonwealth of Independent States (CIS), Japan, and Australia. The U.S. and Canada were granted observer status. The contract came into force on 16 April 1998, when the thirtieth ratification document was filed.

The major objectives of the Energy Charter were:

- To guarantee equal treatment among domestic and foreign investors in each of the signatory states, and to ensure the unhampered repatriation of profits; 
- To enforce WTO rules in the fields of customs and customs tariffs, even in countries that are not members of the WTO;

- To guarantee secure oil transportation, with a special emphasis on the prohibition or interruption of shipments due to political reasons;

- To set up an International Court for the purpose of dispute settlement. The fact that the contract has not yet been ratified by Russia does not reduce the importance of its position as a bulwark against the threat of a general politicization of the development of natural resources and their conveyance in the Caspian region. However, it would be desirable that the most important regional oil producer, i.e., Iran, should be included in the Energy Charter. Up to now, this country was strictly excluded from all negotiations within the framework of the Energy Charter.

The European Union's intention is to establish closer links, based on contracts, with all successor states of the former Soviet Union. For this purpose, the EU has offered them a certain type of "mixed agreements," the so-called partnership and cooperation agreements (PCAs), which create a general framework for cooperation despite the absent element of prospective EU accession. The PCAs with the successor states of the former Soviet Union in the Caspian region consist of political and commercial sections. The commercial part of any given PCA may already have come into force, by means of an interim arrangement, before the final ratification of the PCA itself. The broad field of cooperation opened up by a PCA extends from mercantile trade, monetary transactions, and the protection of investments, and reaches as far as the protection of intellectual property.

In addition, the EU cooperates with the states of the region within the framework of the so-called TACIS program (Technical Assistance to CIS countries). In this context, the INOGATE project (Inter-State Oil and Gas to Europe), being part of TACIS, is of high importance for energy policy in the region. This regional TACIS project is aimed at the reconstruction, modernization, and rationalization of transnational oil and gas pipelines in the Commonwealth of Independent States in general, and in the Caspian region in particular. The cost for the program is approximately fifty million ECU. The goal of the INOGATE project is to develop a number of comprehensive, negotiable proposals in order to enable investments for new pipeline routes, which may be added to those already existing. For this purpose, INOGATE began with the evaluation of the existing supply networks and an assessment of the feasibility of certain infrastructure projects. The program also helped with respect to questions concerning the contract and, for the first time, in 1997, it invested in a number of smaller projects for the redevelopment of important border areas where human and environmental environment were at risk, in order to guarantee continuous energy supply. 


\section{The Problem of the Export Routes for Caspian Oil}

The Caspian Sea, which is really the world's largest lake, has no access to the open sea. This factor, as well as its huge distance from companies that manufacture oil rigs and technical equipment for oil conveyance, increases the production costs for Caspian oil. The EU-as the already mentioned declaration of the EU Council has made clear-places priority on the economically reasonable and cost-efficient solution of the problem, and has started distancing itself from the geopolitical rivalries that have arisen over the export routes for Caspian oil.

The already existing pipelines - the Baku-Novorossiysk and Baku-Supsa routes (the so-called "Early Export Pipelines") — with their combined transportation capacities of three billion tons per year correspond to today's conveyance-mass in the Azerbaijan sector of the Caspian Sea. The increase of oil production to fifty billion tons per year, as scheduled for the year 2005, requires more robust transportation capacities. For this purpose, a main export pipeline (MEP) is being planned to run from Baku to Georgia, and then to the Turkish harbor Ceyhan on the Mediterranean. At the OSCE summit in Istanbul on 18-19 November 1999, the heads of state and government from Azerbaijan, Georgia, and Turkey, with U.S. President Clinton present, signed an agreement on the construction of the Baku-Ceyhan pipeline.

But the economic efficiency of this pipeline, with a flow capacity of up to sixty billion tons per year, is being strongly questioned, because it is uncertain whether Azerbaijan on its own can guarantee the ratability of the pipeline. We can expect that a rentable total function of the pipeline can be achieved by redirecting part of Kazakhstan's oil production over the Baku-Ceyhan route. Until the year 2005, Kazakhstan will provide ten billion tons of oil per year for this purpose. This amount of exports shall be increased up to twenty billion tons per year in the course of the next years.

When the CPC pipeline (which runs from the Tengiz field in Kazakhstan to Novorossiysk in Russia) was opened in the summer of 2001, with a flow capacity of more than 60 billion tons, the possibilities for the realization of the Baku-Ceyhan project became even more questionable. Nevertheless construction for this project had been scheduled to begin in the summer of 2002. The leadership role in the construction consortium was held by British Petroleum. We can expect that the Russian company Lukoil will also participate in the construction work of the pipeline, but this has been strictly denied by representatives of this company.

Other realistic options for the transportation of Caspian oil are linked to plans to build pipelines from Burgas in Bulgaria to Alexandroupolis in Greece, and from Constanza in Romania to Trieste in Italy. In both cases, the solution relies on the shipment of oil over the Black Sea to the respective harbors (Burgas and Constanza), and then further transportation over a network of pipelines. A similar pipeline was constructed from the Ukrainian Black Sea port Odessa to Brody in Western Ukraine, which was finished at the end of 2001.

Regarding the transportation of gas resources in the Caspian region, a number of pipeline projects have been designed so far, but they are still waiting to be carried out. 
The main regional exporter of gas, Turkmenistan, is still highly dependent on Russian transportation networks. This fact delays the development of the country's export capacities, and also has a negative impact on its economic development. The U.S. embargo policy against Iran does not have any positive effect in this respect either. As a result, the only non-Russian pipeline-regardless of U.S. protests - today crosses Iranian territory (Okarem-Kord-Kuy pipeline). However, the capacities of this pipeline are not sufficient to accommodate the scheduled increase of exports. Recently, the deadlocked proposal of a trans-Caspian gas pipeline from Turkmenistan across Azerbaijan and Georgia to Turkey (parallel to the Baku-Ceyhan oil pipeline) has again been strongly pushed by the Turkmen. After the overthrow of the Taliban regime in Afghanistan, the almost forgotten pipeline project from Turkmenistan to Afghanistan and Pakistan has also once again been put on the table.

Today, Azerbaijan is the second largest exporter of gas resources from the Caspian region. The most important route for exporting Azerbaijani gas will, after the completion of the gas pipeline from the Schah-Deniz field in the Azerbaijan sector of the Caspian Sea, run from Tiflis in Georgia to Erzurum in Turkey. The projected flow capacity of this pipeline will be six billion cubic meters per year.

\section{The Question of the Legal Status of the Caspian Sea}

One of the most important obstacles on the road to the broader industrial development of export capacities in the Caspian region has been the unclear legal status of the Caspian Sea. The existing agreements based on international law consist of two agreements that were signed between the Soviet Union and Iran in 1921 and 1940. These agreements are limited to the question of shipment and fishing. Nevertheless, the former superpower USSR considered the Astara (Azerbaijan)-Hasan-Kuly (Turkmenistan) line as the border of its own sector in the Caspian Sea.

With the decline of the Soviet Union, the question of the legal status of the Caspian Sea became extremely contentious, particularly when considered with regard to fossil fuels. Without previous consultations with its neighbors, Azerbaijan signed the socalled "contract of the century" with some well-established Western oil companies to cover the production work in its own sector of the Caspian Sea. Since the adoption of the constitution in 1995, Azerbaijan has viewed this sector as part of its own state territory.

From the Russian point of view, the Caspian Sea was defined as a lake, so that each littoral country had a right over the national twelve-mile zone extending out from its own coastline. Azerbaijan rejected this Russian proposal because this would have meant, in the first place, the loss of the rights to the Azerbaijan offshore fields that lay outside the twelve-mile zone.

Nevertheless, Azerbaijan's President Aliyev and Russia's President Putin reached an agreement featuring a model for dividing the sea bottom into various sectors and governing the general use of the waters of the Caspian Sea in the Baku Declaration, signed on 9 January 2001. Nevertheless, it is frequently pointed out that the final solu- 
tion of the question of the sea's status can only be achieved through a common agreement by all countries in the Caspian littoral.

The current situation with respect to the question of the legal status of the Caspian Sea was the subject for a summit of the heads of state and government of the abutting countries (Azerbaijan, Turkmenistan, Russia, Kazakhstan, and Iran) in Turkmenistan's capital Ashgabat on 23-24 April 2002. Even just before the summit, the positions were relatively clear. On the one hand, one could observe a tendency toward reaching a common understanding between Azerbaijan, Kazakhstan, and Russia on the basis of the previous agreements according to the principle of the "general use of the water surface and division of the sea bottom into a number of sectors." Generally speaking, Turkmenistan was not opposed to this solution, but the question of the oil fields, which was disputed between Azerbaijan and Turkmenistan, prevented an agreement with the other countries. Such an agreement was also prevented by Iran's claims, according to which the sea bottom was to be divided on a pro-rated basis among all littoral countries, i.e., each of them would receive twenty percent.

The summit did not lead to any long-lasting result. On the contrary, tensions rose, and were articulated in emotional statements by several politicians. The Turkmen president Saparmurat Niyazov made threatening gestures to the other participants by saying that there is a "smell of blood in the Caspian Sea." The events of July 2001, when an Iranian gunboat ran off a BP geological research boat with its entire crew from the part of the Caspian Sea claimed by Iran, shows that these threats were not far from becoming reality.

However, there have also been approaches to a pragmatic solution, such as, for example, the Russian-Kazakh attempt to arrive at a juridical segmentation of the northern part of the Caspian Sea. As a result, the presidents of Russia and Kazakhstan, Putin and Nazarbayev, signed the additional protocol to the (6 July) 1998 agreement between the Russian Federation and Kazakhstan over the segmentation of the northern part of the Caspian Sea on 13 May 2002. The goal of the additional protocol was to execute the rights of sovereignty with respect to the exploitation of national resources. This protocol codifies the geographical coordinates of the modified center line and partition in the northern part of the Caspian Sea between Russian and Kazakhstan. President Nazarbayev characterized this protocol as a positive example of a pragmatic approach toward solving this problem. It must be noted that, without a legal solution of the question of ownership in the Caspian Sea, it is impossible to speak of the stable development of the region's existing natural resources.

\section{Turkey, European Energy Security, and the Caspian Region}

As was already mentioned above, Turkey is heavily involved in a number of pipeline projects allowing the transportation of Caspian energy resources to the world market. Beside the sole financial profit out of transit fees, these projects also help to create numerous jobs and to significantly improve the country's own energy supply. 
The various pipeline projects are, of course, also linked to the geopolitical calculations of some powers involved. For example, the U.S. favors the route from Baku in Azerbaijan to Georgia, and then further on to Turkey's harbor Ceyhan at the Mediterranean Sea, a route that circumvents Russia. Despite the fact that many observers have doubts over the cost-effectiveness of this pipeline route, Washington's "Ambassador to the CIS" during the Clinton administration, Stephen Sestanovich, emphasized in 1998 that U.S. policy in the Caspian region is far from being limited to economic interests, and that decisions are also made from a strategic standpoint. To simplify, this strategy can be outlined as follows: First, the pipeline links the regional ally of the United States, Turkey, with two other Western-oriented countries in the Southern Caucasus, Georgia and Azerbaijan, and helps improve the U.S. presence in the entire Caspian region. Second, bypassing Russia bolsters the political and economic independence of the states in the region from their former imperial power. Third, transporting the region's resources without using the low-priced Iranian pipelines increases the isolation of the theocratic regime in Teheran, and also helps avoid any increasing Iranian influence in the Muslim republics of the former USSR.

In the light of the recent rapprochement between the West and Russia, particularly after the creation of the NATO-Russia Council (which gives specific rights to Russia in the political decision-making process within NATO), Turkey and Russia's positions may eventually converge. The quasi-alliance relationship that has become possible between both countries could also initiate further cooperation in the area of petroleum and natural gas pipelines, or even lead to coordinated activities in the fields of regional politics and military cooperation. The official visit of the Turkish General Chief of Staff Hüseyin Kivrikoglu to Russia, and the coordinated activities of the Turkish and Russian presidents with respect to the Kashmir question, can be seen as first signs of such a development. However, at the moment it is too early to give a detailed assessment of their significance.

The Caspian region has become very important for Turkey due to the fact that there is a cultural and linguistic contiguity of the peoples living there. Turkey's relationship with Azerbaijan may be seen as an example. As a consequence, Turkey has helped Azerbaijan set up its own armed forces, and has shown solidarity with this country during its confrontation with its neighbor Armenia in the conflict over the enclave Nagorno-Karabakh. This solidarity went so far that the Turkish government closed down all checkpoints to Armenia until the Armenian army had finally withdrawn its troops from the occupied Azerbaijani territory.

Today, from Turkey's perspective, there are three important tasks to be accomplished in the Caspian region that would legitimize its long-lasting presence and position in the region. First, there is the task of large-scale investment in the Azerbaijani energy industry. Therefore, the Turkish oil company Turkish Petroleum owns 6.75 percent of all shares of the so-called "Contract of the Century," which covers the exploitation of the oil fields in Azerbaijan.

Second, there is the task of pursuing infrastructure projects such as the construction of oil and gas pipelines from Baku to Georgia and then further to Ceyhan and Erzurum. 
The volumes of the gas supplies exported across Turkey will increase significantly in case of the possible realization of the TCP project. Despite American objections, Turkey proceeds with its cooperation with Iran in this domain. Since 2001, Turkey has been receiving gas from there through the Tabriz-Ankara pipeline.

Third, Turkey will assume its coveted role as an energy transport hub, and its importance for Europe's energy supply will increase when all these projects are completed. It will play a distributing function in the so-called "Southern Gas Ring" that is projected by the EU, and, consequently, promote the diversification of the sources of supply (as intended by the EU). As a result, there are also plans to link the Turkish, Greek, and Italian gas networks within the next years. The traditional gas suppliers for the EU have been Russia, Algeria, and Norway. The projected network will enable the newly independent states of the Caspian region to export more gas to Europe.

The projected pipelines will also be significant for Turkey's plans to diversify its own sources of energy. Today, the Russian company Gazprom supplies seventy percent of the Turkish gas demand. In twenty years, domestic demand will increase up to eighty-two billion cubic meters, as estimated by the Turkish Ministry of Energy. We can anticipate that in the coming years Turkish imports of energy resources will exceed by far the domestic demand, so that part of the import could be used for export. 